Article

\title{
Concept Development of Optimal Mine Site Energy Supply
}

Monica Carvalho $^{1, *}$ and Dean L. Millar ${ }^{1,2}$

1 Energy Renewables \& Carbon Management Group, Mining Innovation Rehabilitation and Applied Research Corporation (MIRARCO), 935 Ramsey Lake Road, Sudbury, Ontario, P3E 2C6, Canada

2

Bharti School of Engineering, Laurentian University, 935 Ramsey Lake Road, Sudbury, Ontario, P3E 2C6, Canada; E-Mail: dmillar@mirarco.org

* Author to whom correspondence should be addressed; E-Mail: mcarvalho@mirarco.org; Tel.: +1-705-675-1151 (ext. 6613); Fax: +1-705-675-4838.

Received: 13 August 2012; in revised form: 23 October 2012 / Accepted: 7 November 2012 / Published: 19 November 2012

\begin{abstract}
This paper reports on early work and concept development for Optimal Mine Site Energy Supply, where the specific energy supply requirements and constraints for mineral production operations are considered against methodologies that have been applied for other sectors and in other energy policy regimes. The primary motivation for this research is to help ensure that Canadian mineral producers will achieve reduced production costs through improvements in the efficiency with which they consume energy resources. Heat has not yet been considered for the mining sector in an integrated manner, which makes polygeneration of great interest. The methodology that optimizes configuration of polygeneration systems for mine sites has not been reported before. The variety of mining circumstances, temporal variations in energy prices, institutional inertia, and conservatism in design for mines are some of the reasons for this. This paper reviews some aspects of precedent energy management practice in mineral operations, which highlights energy challenges characteristic of the sector and sets out the initial formulation of optimal mine site energy supply. The review indicates the additional benefits of energy supply systems for mine sites that concurrently meet all utilities.
\end{abstract}

Keywords: optimization; polygeneration; mathematical programming; renewable energy; heat integration; energy management; mineral sector 


\section{Introduction}

Mining is first and foremost a source of mineral commodities that all countries find essential for maintaining their economies and improving their standards of living. Mined materials are needed to construct roads and hospitals, to build automobiles and houses, to make computers and satellites, to generate electricity, and to provide many other goods and services [1]. Both energy consumption within the mining industry and energy prices, are rising and thus there increased need to reduce consumption, and improve primary energy utilization to maintain competitiveness within the mining sector by reducing input costs. Generally, energy supply security and reduced emissions can be achieved through [2]: (1) improvement in energy efficiency; (2) energy savings; (3) higher proportion of renewable energy in supply systems; and (4) process-wide integration.

Given the significance of energy costs in operating expenses, efficiency of energy production and use must be improved in the energy-intensive mining sector [3]. Governments and mining associations recognize the importance of improving energy efficiency, and are working together to implement more energy-efficient technologies. Energy efficiency makes sense for mining operations because it can reduce production cost while simultaneously realizing additional benefits including reduction in the greenhouse gas emissions. While not yet well utilized, process integration and polygeneration are promising tools which reach the double objective of increasing the efficiency of utilization of natural resources, and also of reducing the environmental impact [4].

Polygeneration is a term used to describe a generalization of the cogeneration concept where two (co-generation) or more (poly-generation) energy services are simultaneously provided through use of highly-integrated energy systems. An immediate advantage of polygeneration is its thermodynamically efficient use of fuel. Polygeneration systems utilize otherwise wasted thermal energy, and can use it for space heating, industrial process needs, or as an energy source for another system component. This "cascading" use of energy is what distinguishes polygeneration systems from conventional separate electric and thermal energy systems (e.g., a powerplant and a low pressure boiler), and from simple heat recovery strategies [5]. The deployment of polygeneration systems in mine sites aims at increasing the efficient use of natural resources by combining different technologies, process integration, and energy resources, an objective which may render mineral production operations compliant with the new energy management standard, ISO 50001 [6].

Advantages of polygeneration systems have been demonstrated in the literature $[7,8]$, as energy efficiency is associated with economic savings and sparing of the environment, as less fuel is consumed and consequently less pollution is generated. Such integrated energy systems could play an important role in the gap between fossil fuel-based energy systems and renewable energy-based systems. Polygeneration is a fully developed technology that has a long history of use in many types of industry, particularly in pulp and paper, petroleum and chemical industries, where there is a large demand for both heat and electricity at each site [9]. In recent years, the greater availability and choice of suitable technology options means that polygeneration can become an attractive and practical business proposition.

In recent years, the analysis and design tools for energy systems and energy management have undergone development. In particular, the synthesis and design of energy systems for the industrial sector has become increasingly elaborate, with numerous possibilities for energy sources and 
technological options. This increase in complexity allows for more flexible systems but at the same time increases difficulties when designing the polygeneration system itself.

This paper reports on early work and concept development for Optimal Mine Site Energy Supply, where the specific requirements and constraints of mineral production operations are considered against methodologies that have been applied for other sectors and in other energy policy regimes. Through these extensions, the "most adequate" configurations of energy supply equipment that satisfice (as coined by Herbert Simon [10]) the energy requirements of mine sites in different scenarios and conditions of constraint can be identified.

This paper also presents a critical review of precedent energy management practice in mineral operations, where the thrust has been independent deployment of beneficial technologies. The review indicates the additional benefits of energy supply systems for mine sites that concurrently meet all utilities.

\section{Energy in Mineral Operations}

South Africa's Department of Minerals and Energy estimates that the mining industry uses 6\% of all the energy consumed in South Africa. In Brazil, the largest single energy consumer is mining giant Vale, which accounts for around 4\% of all energy used in the country. In the US State of Colorado, mining has been estimated to account for $18 \%$ of total industrial sector energy use, while overall in the US it is calculated that the mining industry uses $3 \%$ of industry energy [11]. A secure and reliable supply of energy is thus critical for all mining operators to meet their production requirements. For most, energy constitutes a major operating expense and its generation and distribution requires substantial capital investment. To minimize costs, it is important to recognize that energy is a controllable operating cost [12].

Canada is one of the world's leading mining countries and ranks among the largest producers of minerals and metals [13]. Mines, quarries, and primary metal and mineral manufacturing facilities (the mining sector) are distributed across every province and territory [14]. Industrial energy prices increased 58\% for electricity and 310\% for heavy fuel oil in Canada, from 1990 to 2008 [15]; these increases partly illustrate the financial incentive for energy management which aims to allow companies to reduce economic risks resulting from rising energy costs balanced against a need for security of energy supply to ensure continuous production [16]. Between 1990 and 2008, total energy use in Canada has risen by $25.7 \%$, with the mining industry increasing its energy consumption by $137.7 \%$ in the same period [15].

It has been reported [17] that the metal mining industry in the United States has the potential to reduce energy consumption by about $61 \%$ from current practice to the best-estimated practical minimum energy consumption. This reduction was made up of a $21 \%$ reduction by implementing best practices and a $40 \%$ reduction from research and development that improves energy efficiency of mining and mineral processing technologies. Governments, especially in countries with large mining sectors, are imposing standards for energy efficiency. Australia's miners are obliged to comply with the Equipment Energy Efficiency program for energy efficiency. In South Africa, the DME set a target in 2007 for the mining industry to reduce energy demand by $15 \%$ by 2015 [11]. In China, a vigorous 
program was launched in 2004 aimed at reducing energy intensity by $20 \%$ over the period between 2006 and 2010 [18].

Energy management is the judicious and effective use of energy to maximize profits (and minimize costs) and enhance competitive positions [19], while meeting energy demand when and where it is needed (the energy utility). This can be achieved by adjusting and optimizing energy systems and procedures so as to reduce energy requirements per unit of output while maintaining or reducing total costs of producing the output from these systems [20].

Energy management activities are often categorized into supply side management or demand side management activities. As mineral production businesses are frequently vertically integrated businesses that hold their own generation [21] and/or transmission [22] and/or distribution assets, as well as maintaining control of their own demand centers, both sides of the energy system (supply and demand) are of concern in energy management practice.

Demand Side Management (DSM) can be defined [23] as the planning, implementation, and monitoring of distribution network utility activities designed to influence customer use of electricity in ways that will produce desired changes in the load shape. The goal of DSM is to smooth out peaks and valleys in energy demand to make better use of energy resources and defer the need to build new power plants. There are four broad categories of load-shape DSM objectives: peak clipping, strategic conservation, valley filling, and load shifting, as illustrated in the extreme right side of Figure 1. In Figure 1, sources of demand running continuously are shown in red, variable or intermittent loads are shown in green and those that may change from base load to intermittent loads are emboldened. Activities in the framework that are new are shown in dashed lines.

Figure 1. Preliminary framework for energy management activities in an underground mine [3].

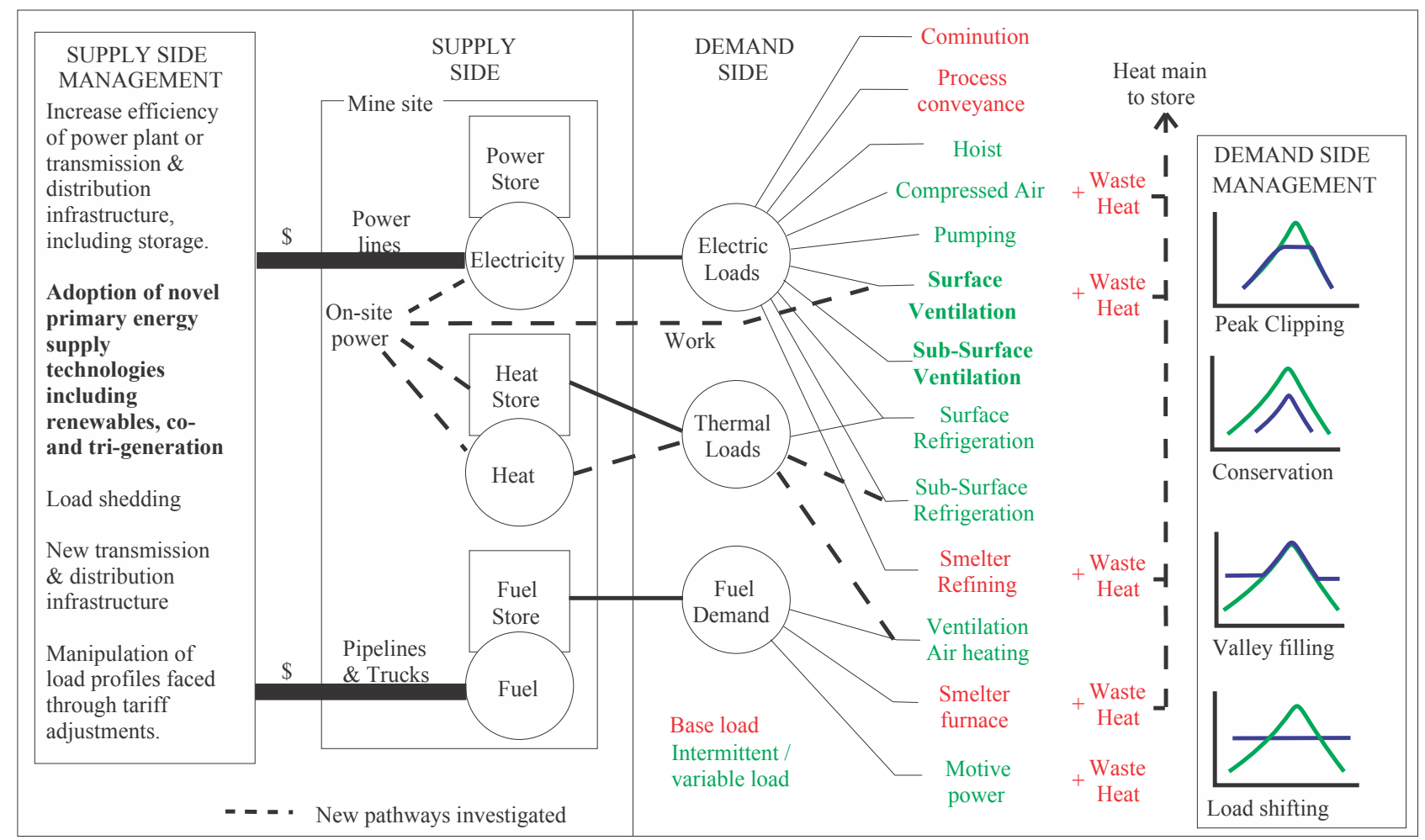


Supply-side management (SSM) refers to actions taken to ensure the generation, transmission and distribution of energy are conducted efficiently [24]. Effective SSM actions will usually increase the efficiency with which demand centers are supplied, allowing installed generating capacity to provide electricity at lower cost (permitting lower prices to be offered to consumers) and reducing environmental emissions per unit of end-use electricity provided. Exemplary SSM activities are illustrated on the extreme left side of Figure 1, but could extend to emissions trading, construction of primary energy storage and distribution facilities [3].

The potential economic benefits of a high energy consumption intensity for mineral production (see for example [25]) lead to consideration of local (mine site) elements of supply side energy management. One example of supply side energy management is the adoption of energy supply technologies including renewable energy and polygeneration. As heat has not yet been considered for the mining sector in an integrated manner, polygeneration is of great interest for the sector. Renewables and polygeneration options are the new pathways that are subject to the current investigations.

\section{Polygeneration Technology}

The increase in energy utilization efficiency is, without doubt, the main advantage of producing different energy services (heat, coolth [26], and electricity) in one installation from the same energy source. Furthermore, polygeneration schemes can generate many configurations and thus allow for ample design flexibility that accommodates specific regional conditions [27]. However, choosing the correct size and design of a polygeneration system is a key factor for the success of the project: undersized systems do not realize the profit of exploiting the whole polygeneration potential of the site, and if the system is oversized low or negative primary energy savings may be obtained [28].

In the case that the energy supply system has already been built, the optimization procedure will encompass only the operational strategy. However, if external conditions change (energy demands, utility prices, etc.), a retrofit adopting additional equipment is added to the existing system (the configuration of which then comprises a constraint on optimization). For new systems, in addition to the optimal dispatch of energy supply plant the optimal system configuration must also be identified (essentially the specification of equipment in rating and number) $[29,30]$.

A general thermoeconomic framework has been established [31-35] to identify optimal combinations of energy conversion and delivery technologies, as well as operating rules for systems installed in tertiary sector buildings. A reference/conventional system for production of electricity, heating and coolth to attend the demands of a building is shown in Figure 2, where all electricity is purchased from a utility company owned electricity distribution grid to either meet the electricity demand directly or produce cooling in mechanical chillers driven by electrical motors, and heating demand is produced by a natural gas boiler. The aforementioned framework, described as an energy superstructure [31], is shown in Figure 3, containing all technology alternatives that may be adopted (but not their ratings or numbers). D, S, P and W refer to, respectively, demand, sale, purchase and waste (loss) of a utility. Within Figure 2 and 3, the horizontal or vertical lines essentially represent physical distribution systems into which the technologies indicated can feed in energy of a specific form. Site loads for energy in that specific form (a specific energy utility) are supplied from that 
distribution system, including further energy conversion technologies that convert the supplied utility into another form (which in turn supplies another distribution required by the site loads).

Figure 2. Reference system.

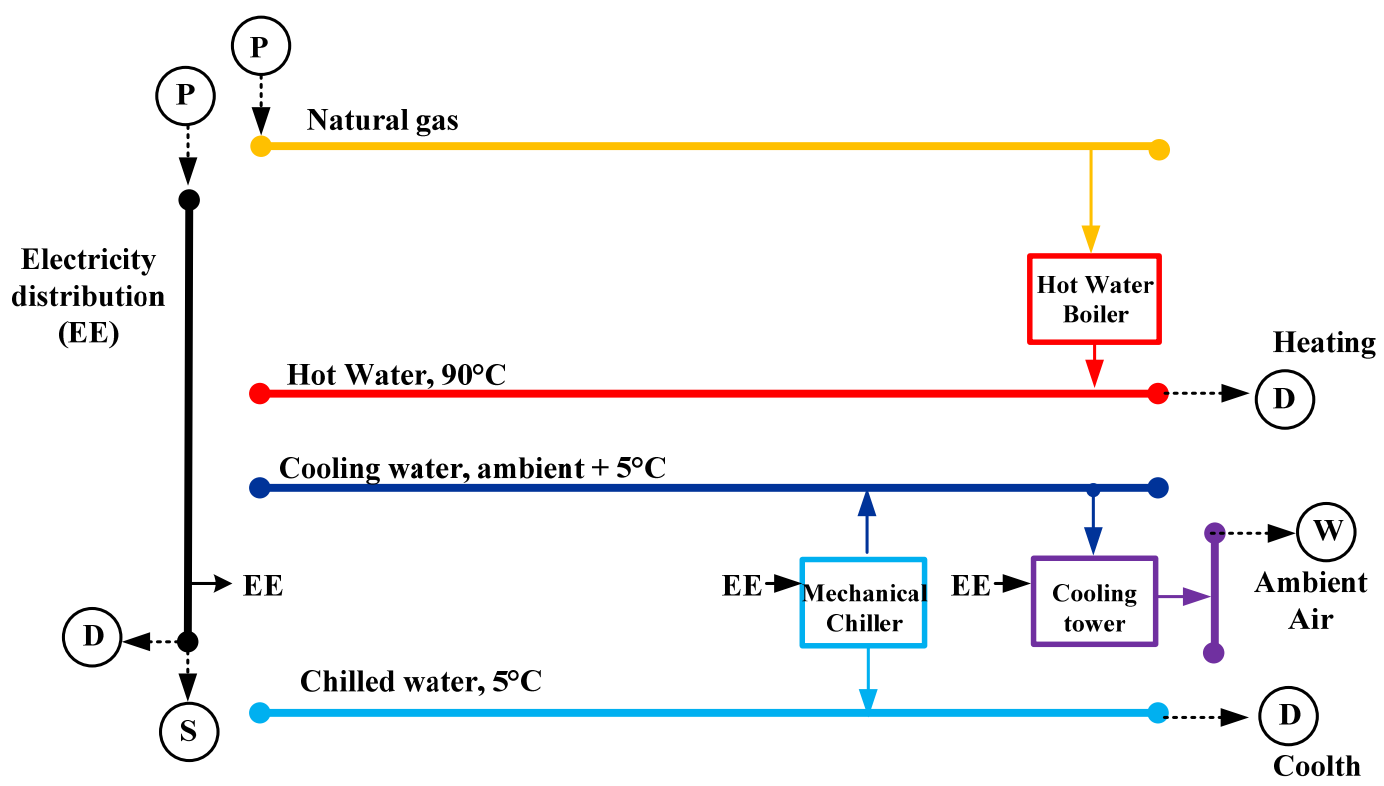

Figure 3. Superstructure of an energy supply system for a building.

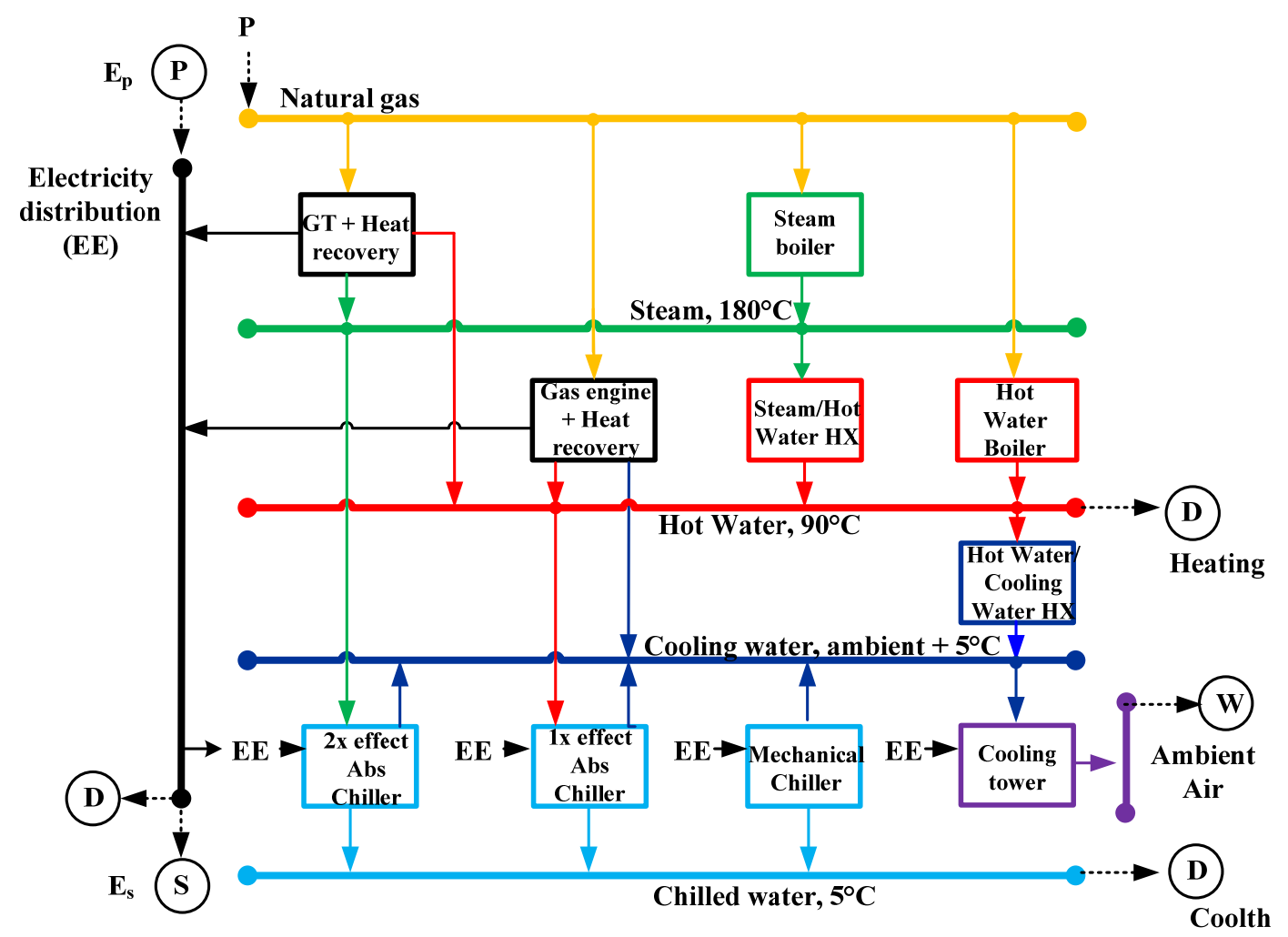




\section{Optimal Mine Site Energy Supply_OMSES Initial Formulation}

For simplicity and tractability, no dynamic process models for any of the components are adopted. Instead, each technology is assigned coefficients defining their performance in energy conversion. As the technology models are not dynamic, no temperature attribute is available for the technologies, which precludes an exergetic formulation of the optimization analysis. An exergetic formulation may be the subject of future developments, nevertheless, in the same way that the prior framework has been found useful in the tertiary sector buildings, it is been found of equal value in the mining industry.

For energy services superstructures such as those presented in Figures 2 and 3, following precedent practices [33-35], the decision variables for an optimization problem formulated to determine the optimal mine site energy supply may be characterized as follows:

1. binary variables (denoting whether a technology is/is not installed);

2. integer variables (denoting the number of installed units of a technology);

3. continuous variables (denoting the energy flows between utilities). The latter include connections to distribution systems across the site boundary (to the utility company's electrical and natural gas distribution systems - where appropriate) and energy flows between distributions and site loads.

Figure 4. Showing (LHS) a cut-away diagram of a Cat ${ }^{\circledR}$ G3616 gas engine [36] and (RHS) the energy flows for this technology normalized to the electrical energy output. (Reprinted courtesy of Caterpillar Inc.)

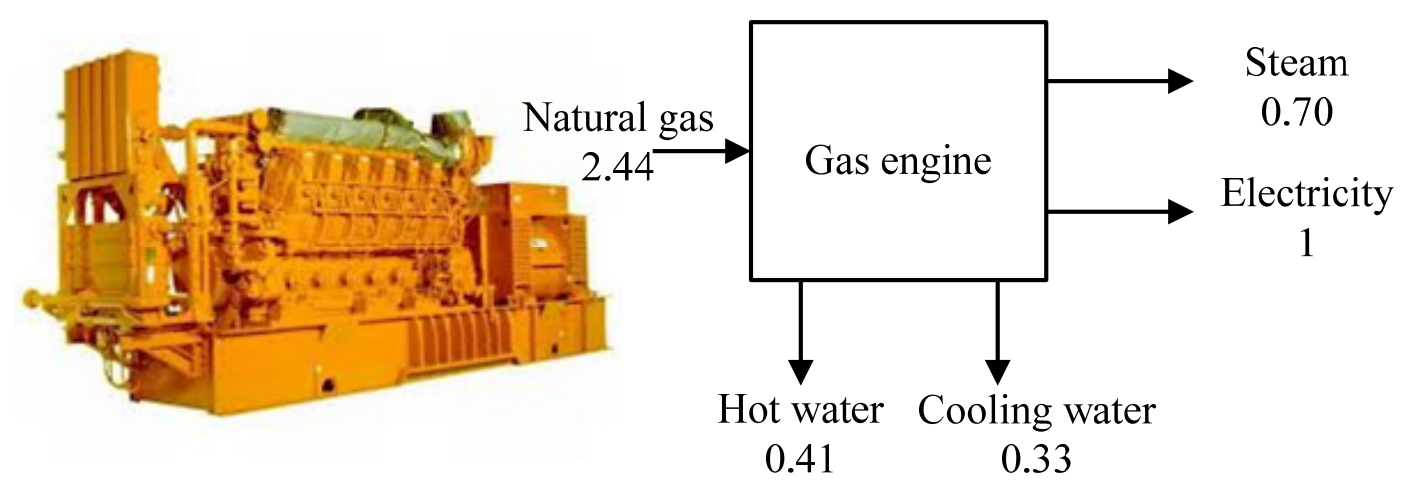

The constraints that may be taken to apply to the optimization process are manifold:

1. Energy conversion technology constraints. These are constraints that reflect an energy conversion mass and energy balance across each technology of a specific type. A graphical example representation of such a constraint is presented in Figure 4 which shows the energy (and inferred mass) balance across a gas engine equipped with a heat recovery unit.

2. Technology installation limit constraints. These constraints apply a threshold on the maximum number of units of a given technology type that may be installed. Such a constraint is useful to reflect practical considerations such as the amount of land footprint available to accommodate technology of a specific type. This also articulates a capacity constraint for the specific technologies.

3. Utility balancing off constraints. These are constraints that ensure that the net sums of energy flows from each of the indicated distributions are zero, which also ensure that energy supply (in all its forms) meets on-site demand. In the event that hourly on-site demand data are available for an entire 
year, 8760 such constraints feature in the problem formulation, for a specific utility. In practice, various heuristics may be deployed to reduce the number of these constraints (e.g., considering only 12, 24 hour periods, each representative of a typical day in a typical month - see Figure 5).

4. Carbon dioxide equivalent emissions constraints. These are constraints that express the idea that the total emissions associated with the production of energy from the energy services system falls below a given threshold. In prior formulations (e.g., $[33,34]$ ), such emissions include those attributable to the materials (manufacture and installation of the technologies at the site) and operation of the system.

5. Energy market constraints. These include inter alia thresholds on the quantities of energy that may be procured externally, exported off-site, or wasted.

Figure 5. Heating and cooling demand profile projections for a $2500 \mathrm{~m}$ deep mine located in Canada at latitude $46^{\circ}$ North.

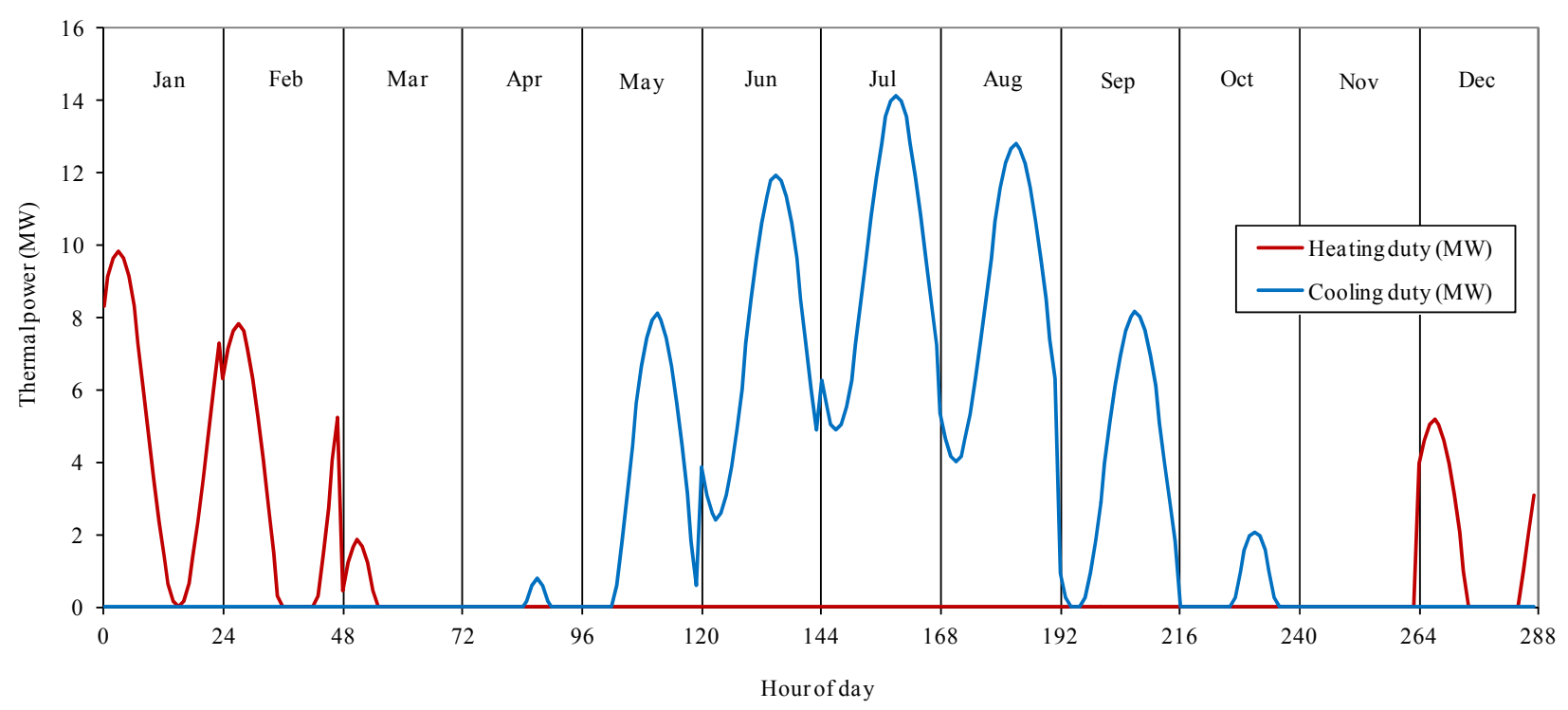

The objective function for the optimization process is defined in economic terms, expressed as a minimum total cost of meeting the on-site energy demand. Various components are considered in its formulation. Principally, the total cost is decomposed into an annuitized fixed cost element and a variable cost element.

The fixed cost element thus accounts for the discounting process and the time value of money, as well as the replacement/major overhaul interval of the technology. The variable cost element is primarily expressed in terms of the unit cost of procurement of energy in a particular form, supplied to the site, multiplied by the volume of that energy used in a specified time period. Through constraints taken to apply in the optimization process, this cost element may reflect particular operational strategies imposed, for example, a user-defined decision to operate bespoke co-generation plant components at full load.

As it is within the scope of the energy services infrastructure to export energy in various forms off the site, revenues arising from any such sales are treated as negative costs.

The scheme can be extended to a multiobjective optimization through the inclusion of economic and environmental components of the objective function with weighting factors or through the addition 
of environmental constraints on an economic-only based objective function. The environmental components can be expressed in terms of carbon emissions, greenhouse gas emissions or aggregated indicators, such as Eco Indicator-99 [37].

Given the nature of the decision variables indicated, in prior deployments Mixed Integer Programming (MIP) has been found effective in establishing optimal configurations and equipment operating strategies, this technique having been broadly applied in production planning, sequencing processes, distribution and logistics problems, refinery planning, power plant scheduling, and process design. MIP captures the complexity of polygeneration systems in synthesis problems such as that described for optimal on-site energy supply. Formulation of the problem in MIP compatible terms presents opportunities to benefit from significant recent advances in the mathematical programming field such as those found in [38].

\section{Characteristic Challenges of OMSES}

Mining operations in Northern Canada can also face a particular energy challenge given the lack of grid (electric and gas) capacity and limited infrastructure. In addition, it is typical for underground mines to require progressively more energy to access and extract the minerals as operations mine deeper. Deep mines (nominally $>2,000 \mathrm{~m}$ ) acquire substantial cooling loads as they age, and meeting such important energy demands is becoming economically and technically important.

Opportunities for savings offered by adoption of polygeneration have not been investigated in depth previously for the specific cases of mine sites, possibly for the following reasons: (1) wide variety of technology options for the provision of energy services; (2) temporal variations (diurnal, seasonal and inter-annual) in energy prices; (3) temporal variations (diurnal, seasonal) in climate; (4) temporal variation (diurnal, seasonal and inter-annual) in energy demand; and (5) institutional inertia, and conservatism in mine design for mines.

Diurnal, seasonal and inter-annual variability of thermal loads in the mining sector in Canada increase the complexity of generic energy supply systems and solutions of high sophistication are required for operation to be economically attractive. Mine air heating and cooling loads are seasonally complementary (see Figure 5). The timing of the highest cooling loads in summer seasons, if serviced by a mechanical chiller system, is at odds with electricity tariff peak times.

In Figure 5, thermal demand profile projections are illustrated for a study period of one year, distributed as 12 days, each day taken as typical for each month and divided into 24 hourly periods (at 2,500 $\mathrm{m}$ depth, base temperatures were: for heating $=18{ }^{\circ} \mathrm{C}$; for cooling $=30^{\circ} \mathrm{C}$ ).

Applying optimization techniques to the problem of mine-site energy supply presents some unique challenges: variability of energy loads which will always remain variable, but may be highly predictable (e.g., those due to winding and groundwater pumping activity in the case of electricity), the need to produce from deeper, hotter levels, as in Canadian climates with extreme climatic variation, and in remote areas with no connection to the electric or gas grids. These characteristics are not seen as insurmountable and offer potential for innovation as indicated below. 


\section{Extensions to Core Methodology}

\subsection{Integration of Renewable Energy Technologies}

Primary energy inputs from new and renewable energy resources and technologies are considered, with characteristics of intermittency and variability, alongside conventional energy supply technologies, as shown in Figure 6. Potential advantages are set out by Trapani \& Millar in [39], for remote mining operations. Renewable energies are introduced as available utilities in the synthesis, design and operation of energy systems, which is generically applicable to renewable energy integration studies for other industries too.

Figure 6. Superstructure of an energy supply system for a mine.

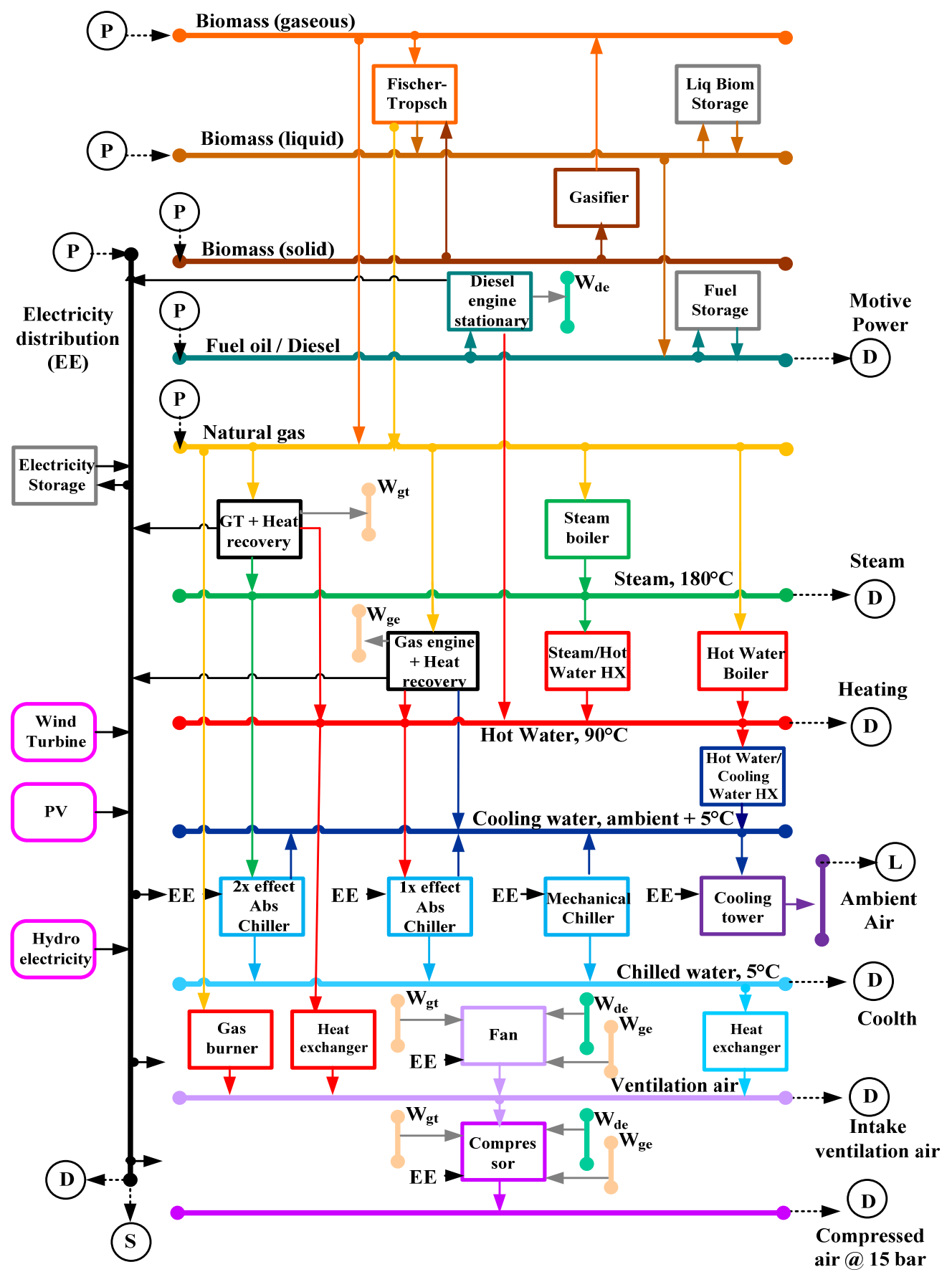




\subsection{Integration of Energy Storage Technologies}

Energy storage systems will also be considered as utilities on the supply side and as dispatchable loads on the demand side. On-site energy storage technologies are included to compensate for the variable and intermittent characteristics of renewable energy sources. Integration of storage technologies into the energy supply optimization process may introduce less constraint into the resulting energy supply system, and consequently could lower energy supply cost, equivalent $\mathrm{CO}_{2}$ emissions, or both. Many of the technical challenges in reformulating the mathematical optimization procedures to accommodate intermittent and variable renewable energy supply utilities, may be reapplied in consideration of energy stores acting as energy supply components.

\subsection{Part Load Operation of all Technologies}

A common practice to facilitate the operation of a system is to consider that cogeneration modules operate at full load when in service. This study will go a step further by considering that energy balance data varies with load conditions for all technologies. As a consequence of considering part load operation, a more heterogeneous range of technologies may emerge in optimal solutions. Part load operation of prime movers gain importance as it suits off-grid analyses.

\subsection{Consideration of Work from Prime Movers as a New Utility}

On mineral production sites, some processes that form part of the electricity base load fundamentally constitute a demand for energy in the form of work $\left(\mathrm{W}_{\mathrm{de}}, \mathrm{W}_{\mathrm{gt}}\right.$, and $\mathrm{W}_{\mathrm{ge}}$ in Figure 6$)$, which could be met by the prime mover of a polygeneration system. Examples of the latter could include surface pumping, production of compressed air, and the running of main ventilation fans on surface.

\subsection{Work in Progress}

A database and models of the potentially installable equipment is currently being adapted through the addition of equipment with larger rating (commensurate with that needed for large industrial applications, such as mining). It contains investment, operation, performance and environmental information on each technology that may be considered. The latter informs Life Cycle Analysis that sets and coordinates criteria in the multiobjective optimization (economic/environmental trade-off).

Energy demands are characterized for mine sites, and the collaborators will also supply data on the purchase/sale tariffs of the different utilities (when available). The exemplar consumer centers to be used in this extension are located in Northern Ontario (Canada), with energy demands varying seasonally and diurnally. The consumer centers are mineral productions operations that are connected to energy supply infrastructure and those that are not.

\section{An Example Application}

A simple case study is considered to prove and illustrate the validity and usefulness of the proposed methodology. Real electricity data is available from a process plant, along with estimated heat (space heating plus sanitary hot water), coolth and electricity demands for mine office and dormitory 
buildings (accommodating approximately 400 employees). The monthly-average ambient temperature was used to calculate the monthly heat/coolth/electricity demand distribution and also the hourly ambient temperature and degree-days [40] of the office and dormitory buildings. Real demands for diesel from mobile equipment were available and were introduced into the optimization model.

The annual energy demands for the mine operation were: 2,356 MWh for heat, $354 \mathrm{MWh}$ for coolth, 119,730 MWh for electricity and 102,667 MWh of diesel. One operational year was considered in the study, divided into 12 representative days (one day per month, as no significant difference was identified between weekdays and weekends), subdivided into 24 hours.

The extensions required development of a more generalized superstructure to describe the system and to visualize results, as shown in Figures 7 to 9, where the possible technologies, available energy utilities and their interactions can be observed. A positive node denotes a technology that supplies the distribution. A negative node denotes a technology that consumes from the distribution. Within Figure 7, the horizontal essentially represent physical distribution systems into which the technologies indicated (the vertical lines) can feed in or draw energy of a specific form. Site loads for energy in that specific form (a specific energy utility) are supplied from that distribution system, including further energy conversion technologies that convert the supplied utility into another form (which in turn may supply another utility distribution required by the site loads).

Figure 7. Initial superstructure for example application illustrating all potential conversion pathways considered.

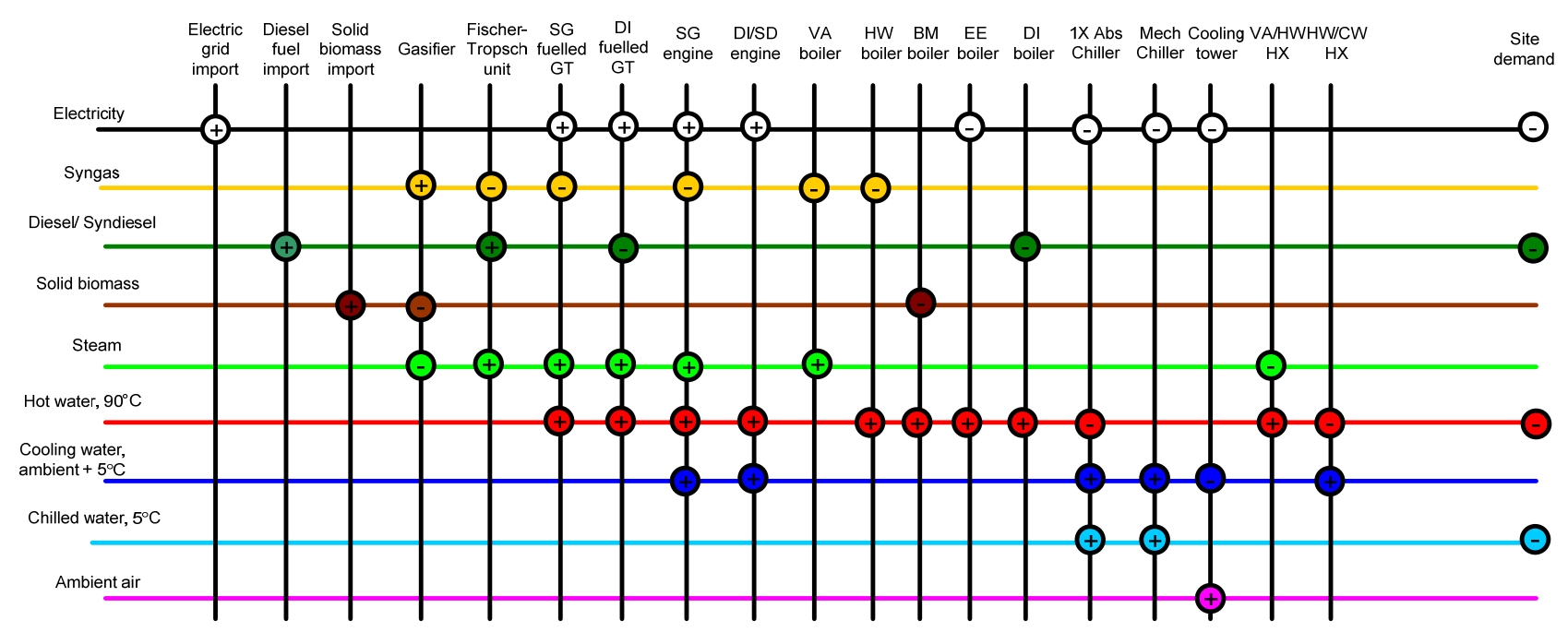

The available utilities for purchase were solid biomass (BM), electricity (EE), and diesel (DI). A natural gas grid is assumed not available at this location. A gasification unit to convert solid biomass into a combustible gas also introduced new thermal loads into the model [41]. Gasified products could be utilized in a Fischer-Tropsch process to produce syndiesel [42]. Diesel fuelled hydraulic excavators, haulage trucks well as static prime movers for electricity generation draw from the diesel utility. Energy consumption from mobile plant is thus assimilated into the polygeneration optimization model.

Other available utilities were syngas and syndiesel (SG, SD, respectively), steam (VA, $180{ }^{\circ} \mathrm{C}$ ), hot water $\left(\mathrm{HW}, 90{ }^{\circ} \mathrm{C}\right)$, cooling water $\left(\mathrm{CW}, \mathrm{t}_{0}+5{ }^{\circ} \mathrm{C}\right)$, ambient air $\left(\mathrm{AA}, \mathrm{t}_{0}{ }^{\circ} \mathrm{C}\right)$, and chilled water $(\mathrm{CO}$, $\left.5^{\circ} \mathrm{C}\right)$. In Figure 7, GT denotes gas turbine and $\mathrm{HX}$ denotes heat exchanger. 
Table 1 shows the equipment selected for inclusion in the superstructure, along with the production coefficients normalized to the main product of the equipment (indicated in bold). The capital cost of the equipment and nominal power are also included in Table 1. The lifetime of the system was considered to be 20 years and the discount rate, $10 \%$. The price for electricity purchased from the grid or sold to the grid was CAD 100 per MWh. The price of imported diesel was taken to be CAD 130 per $\mathrm{MWh}$, which is approximately equivalent to CAD 1.35 per litre, the consumer pump price prevailing at the time of writing. The price of purpose grown solid biomass was CAD 30 per MWh, which is approximately equivalent to CAD 135 per tonne (at $16 \mathrm{MJ} / \mathrm{kg}$, dry) [43]. There can be multiple units of each technology.

For the purposes of this illustrative example only, no environmental constraints were admitted into the formulation.

The example application was formulated precisely following the methodologies set out in detail in [31]. The optimization process simultaneously identifies the optimal combination and number of technologies (selected from those listed in Table 1) and the optimal policy for their operation. This means, for example, that the results of the optimization process may reveal the hourly amounts of biomass and diesel fuel that may need to be procured, or produced on-site, by the mine operator in order to secure the capacity to produce. This base case mine is assumed grid connected with any surplus electricity utility being exported so that it may be imported subsequently. The formulation thus allows the electric grid to behave as an energy store with unlimited storage capacity. Other than the absence of a threshold of energy stored, the formulation to consider storage schemes for, for example, diesel, are similar. Referring to the nomenclature used in [31] this threshold can be mathematically expressed as:

\section{$\mathrm{CDIH}(\mathrm{kd}, \mathrm{kh}) \leq \mathrm{ILIMIT}$}

where $\mathrm{CDIH}(\mathrm{kd}, \mathrm{kh})$ is the purchase of diesel at each day $(\mathrm{kd})$ and hour $(\mathrm{kh})$, and DILIMIT is a number which indicates the maximum purchase allowed for diesel at each day and hour. A different threshold could also be implemented by considering a fixed-capacity storage, which would be replenished only by winter road (in February, for example). Therefore the cumulative sum of the consumption from March to January, for example, should be lower than TLIMIT, where TLIMIT is the capacity of the storage tank.

As there were 68,000 decision variables, 101,000 non-negativity constraints and 43,000 technical constraints, it is not practical to report the results of the optimization process in detail. Instead, we report aggregated quantities found from the detailed results typically reflecting annual performance indicators and show only those utilities and technologies that are part of the optimal mine site energy supply. The configuration of the optimal base case solution is shown in Figure 8, along with main energy flows. 
Table 1. Selected equipment and matrix of production coefficients.

\begin{tabular}{|c|c|c|c|c|c|c|c|c|c|c|c|}
\hline Equipment & $\begin{array}{c}\text { Capital Cost } \\
\left(10^{3} \$\right)\end{array}$ & $\begin{array}{c}\text { Nominal Power } \\
\text { (MW) }\end{array}$ & Biomass & Electricity & Syngas & Diesel & Steam & $\begin{array}{c}\text { Hot } \\
\text { Water }\end{array}$ & $\begin{array}{l}\text { Cooling } \\
\text { Water }\end{array}$ & $\begin{array}{l}\text { Chilled } \\
\text { Water }\end{array}$ & $\begin{array}{c}\text { Ambient } \\
\text { Air }\end{array}$ \\
\hline Gasifier & 3000 & 3.0 & 1.54 & & 1 & & 0.06 & & & & \\
\hline Fischer-Tropsch unit & 4000 & 3.0 & & & 1.25 & 1 & 0.60 & & & & \\
\hline Gas turbine & 4000 & 3.6 & & 1 & 3.03 & & 0.59 & 0.66 & & & \\
\hline Diesel turbine & 4000 & 3.6 & & 1 & & 3.00 & 0.60 & 0.60 & & & \\
\hline Gas engine & 3600 & 3.6 & & 1 & 2.44 & & 0.70 & 0.41 & 0.33 & & \\
\hline Diesel engine & 4400 & 4.4 & & 1 & & 2.27 & & 0.80 & 0.20 & & \\
\hline Steam boiler & 144 & 3.0 & & & 1.18 & & 1 & & & & \\
\hline Hot Water Boiler & 150 & 3.9 & & & 1.22 & & & 1 & & & \\
\hline Biomass boiler & 492 & 3.5 & 1.25 & & 0.06 & & & 1 & & & \\
\hline Electric boiler & 144 & 3.0 & & 1.11 & & & & 1 & & & \\
\hline Diesel boiler & 170 & 3.8 & & & & 1.25 & & 1 & & & \\
\hline 1X Abs Chiller & 280 & 1.5 & & 0.01 & & & & 1.36 & 2.36 & 1 & \\
\hline Mechanical Chiller & 680 & 2.7 & & 0.21 & & & & & 1.21 & 1 & \\
\hline Cooling Tower & 185 & 7.4 & & 0.02 & & & & & 1 & & 1 \\
\hline Steam-Hot W HX & 50 & 5.0 & & & & & 1.1 & 1 & & & \\
\hline Hot W-Cool W HX & 35 & 5.0 & & & & & & 1.1 & 1 & & \\
\hline
\end{tabular}


Figure 8. Optimal base case solution, displaying technologies installed and main annual energy flows. The annuitized capital cost is $140,070 \mathrm{CAD}$, and the annualized operation cost is $25,636,444$ CAD.

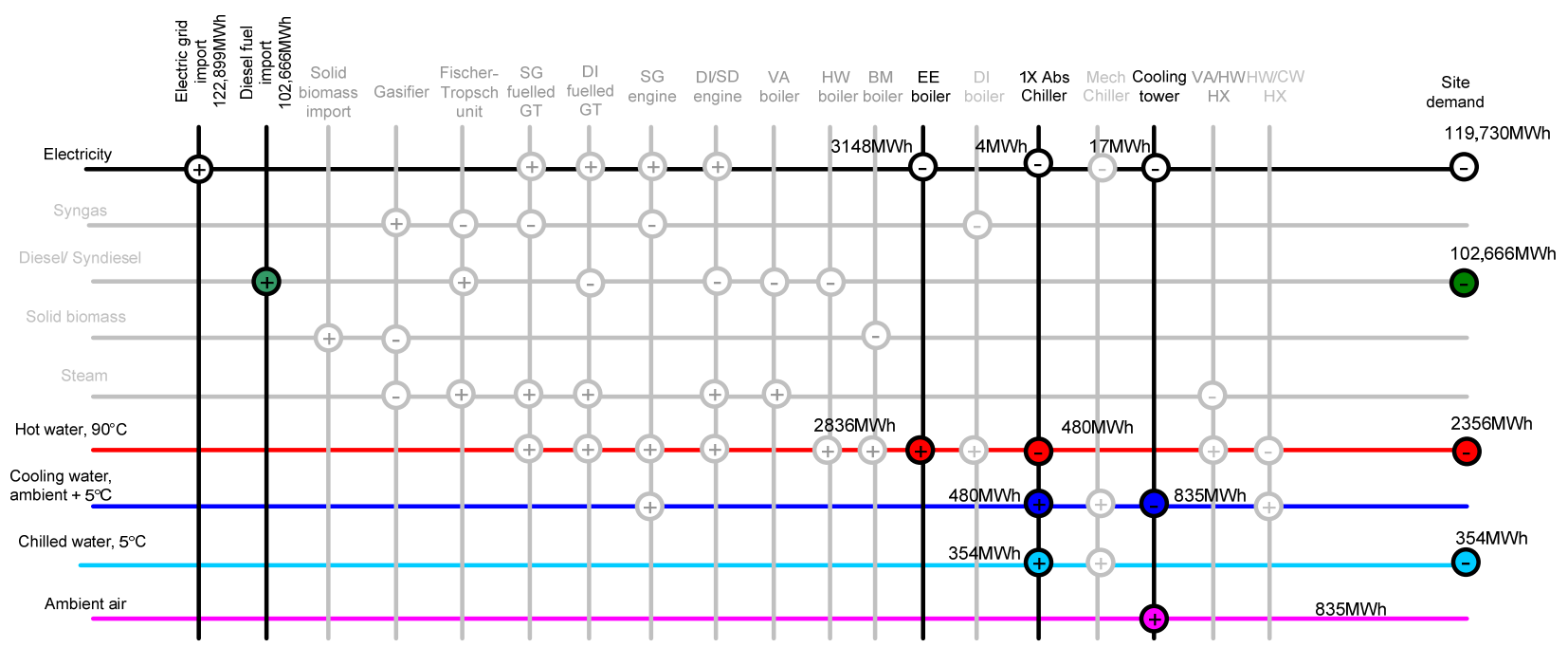

The optimal base case solution installs one electric boiler, one single effect absorption chiller and one cooling tower. The heat from the electric boiler covers the heat demand and also the coolth demand through the absorption chiller. The cooling tower is used to evacuate all the cooling water heat from the chiller. The annuitized capital cost of the optimal base case solution is 140,070 CAD, and the annualized operation cost is $25,636,444$ CAD.

If, however, we consider the base case mine to be off-grid mine with the aforementioned technical and economic scenario, the optimal solution changes drastically. Preclusion of the possibility of purchasing electricity forces the system to change to the configuration shown in Figure 9. Five syngas-fuelled engines are installed, along with one absorption chiller, 15 gasifiers and three Fischer-Tropsch units. Biomass is purchased to feed the gasifiers, which produce syngas to operate the gas engines and the Fischer-Tropsch units. In this case, the annuitized capital cost of the optimal solution is 17,508,750 CAD, and the annualized operating cost is $22,438,577$ CAD. This solution presents an increase in annual cost of $55 \%$, however had the base case mine been considered remote from the existing transmission and distribution electricity grid, the annuitized capital cost of extending high tension lines to the mine site would become relevant and would equalize the total annual costs of the off-grid mine at a break-even extension distance. The technologies and main energy flows of this re-optimized solution are shown in Figure 9.

This formulation for optimal mine site energy supply may be used to investigate additional trade-offs. For the base case mine, an interesting analysis is to identify the diesel price at which there is a switch from direct diesel purchase to the installation of gasifiers + Fischer-Tropsch units for the production of syngas and syndiesel. A series of parametrically driven re-optimizations identified that when diesel prices almost double to $250 \mathrm{CAD} / \mathrm{MWh}$, the optimal solution installs 4 gasifiers producing syngas to drive a gas engine and to fuel one Fischer-Tropsch unit. 
Figure 9. Off-grid optimal base case solution, showing technologies installed and main annual energy flows. The annuitized capital cost is $17,508,750 \mathrm{CAD}$, and the annualized operating cost is $22,438,577 \mathrm{CAD}$.

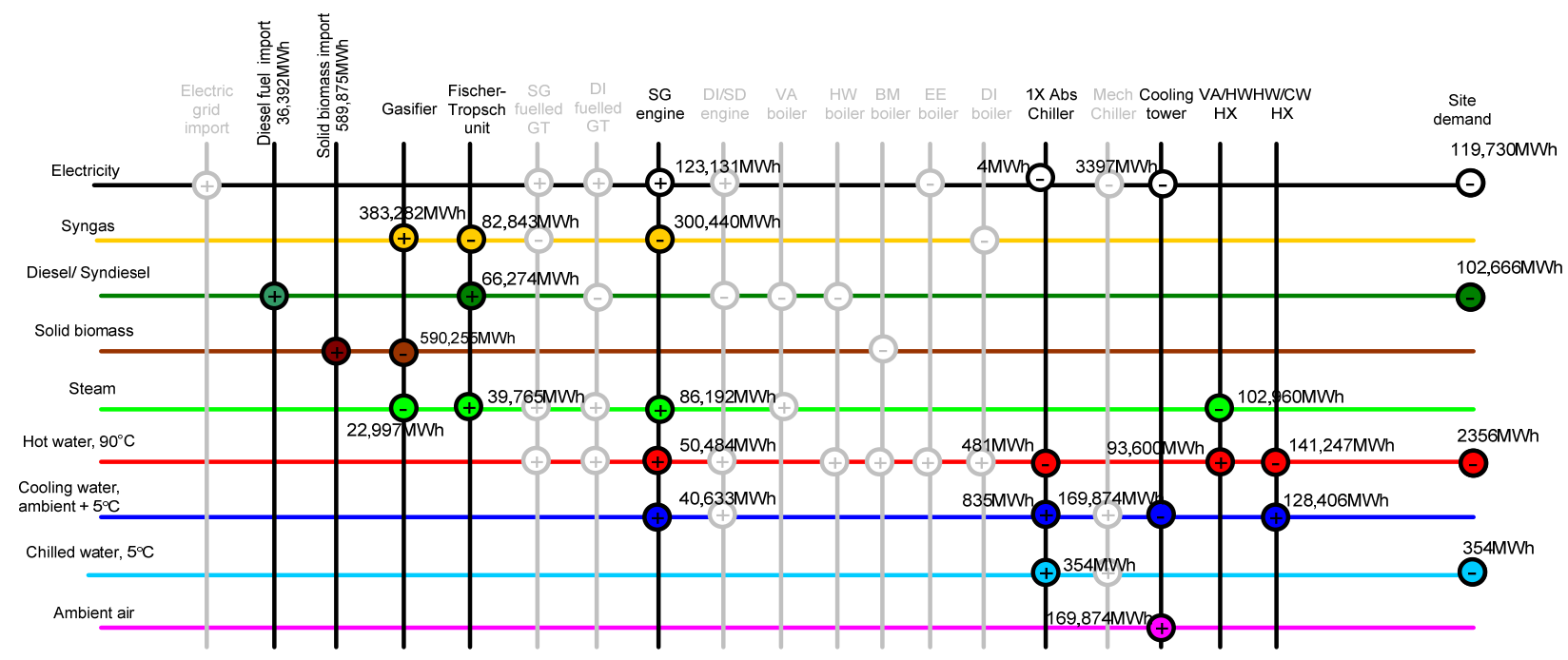

It is also interesting to verify the biomass starting point for the installation of gasifiers. The price utilized in the model considers purpose-grown biomass and transportation. However, peat fuel-a biomass energy source-is abundant in Northern Ontario [44]. In this case, the biomass procurement cost would be much reduced as the resource is close to, or on-site. At a price of $12 \mathrm{CAD} / \mathrm{MWh}$ for peat (equivalent to approximately $55 \mathrm{CAD} /$ tonne), the re-optimized solution includes the purchase of biomass to feed gasifiers and then Fischer-Tropsch units.

As stated in the opening of the paper, this is work in progress, however the value of the optimal mine site energy supply formulation in decision support for mining operations has been clearly illustrated in these simple examples. The objective of this paper was to present the concept of developing energy supply solutions for mining operations in Canada, to reflect the challenges faced by the mining sector that must be overcome, and the extensions that will be implemented in order to achieve energy efficiency goals.

\section{Conclusions}

This contribution outlines the priorities of investigation, development and demonstration of new concepts and technologies to improve energy efficiency and reduce final consumption of primary energy in the mining sector, considering the life cycle holistically. Due to the energy-intensive nature of mining operations, energy is a significant component of total mine operating costs and a reduction in energy consumption may directly result in cost savings. It is expected that energy procurement costs will increase in the future adding to the incentive to effectively manage energy [12] in the sector.

The analysis of thermal process integration has contributed to the improvement of the efficiency of cogeneration systems used in the industry sector, and its application to polygeneration systems with thermal storage and possible support of renewable energies will reveal the most cost effective or low carbon configuration and operational strategy. Scenarios with substantial economic potential in which 
renewables are advantageous, alone or in combination with cogeneration systems have been identified, while a priori both are energy production systems that compete.

The design techniques developed will facilitate the collaboration of equipment manufacturers in the development and commercialization of modular systems. The development of new products and the techniques involved will contribute to a greater competitiveness of the participating companies and, what is equally important, to decrease the energy costs of the consumer center.

Although the research is applied and has a Canada focus, in terms of the case studies adopted, the work is of global scientific importance. The local dimension, even the specific industry focus, is just a way in which the relevance of the science is demonstrated. Theoretical extensions (storage, renewables) are of generic applicability for all integration studies. The mining sector is used as an example to drive and exemplify the methodological development process.

\section{Acknowledgments}

This work was developed within the framework of research projects Smart Underground Monitoring and Integrated Technologies for Deep Mining (SUMIT, funded by Ontario Research Fund for Research Excellence Funding-Round 5), and Optimal Mine Site Energy Supply (OMSES, funded by Natural Sciences and Engineering Research Council of Canada through an Industrial Research \& Development Fellowship). Thanks are extended to DeBeers Canada, Hearst Community, and the Ontario Geological Survey (unit of Ministry of Northern Development and Mines).

\section{References and Notes}

1. Natural Research Council. Evolutionary and Revolutionary Technologies for Mining; Committee on Technologies for the Mining Industries: Washington, DC, USA, 2001.

2. Liu, P.; Georgiadis, M.; Pistikopoulos, E. Advances in Energy Systems Engineering. Ind. Eng. Chem. Res. 2011, 50, 4915-4926.

3. Millar, D.; Levesque, M.; Lyle, G.; Bullock, K. Enabling progressive energy management practice for minerals operations. Can. Inst. Min. J. 2012, 3, 178-184.

4. Serra, L.M.; Lozano, M.A.; Ramos, J.; Ensinas, A.V.; Nebra, S.A. Polygeneration and efficient use of natural resources. Energy 2009, 34, 575-586.

5. Stuckel, J. Industrial and Commercial Cogeneration. Office of Technology Assessment Archive: Washington, DC, USA, February 1983. Available online: http://www.fas.org/ota/reports/8311.pdf (accessed on 22 October 2012).

6. Energy Management Systems-Requirements with Guidance; International Organization for Standardization (ISO): Geneva, Switzerland, 2011.

7. Maglorie, P.; Heteu, T.; Bolle. L. Economie d'énergie en trigénération. Intern. J. Therm. Sci. 2002, 41, 1151-1159.

8. Chicco, G.; Mancarella, P. Distributed multi-generation: A comprehensive review. Renew. Sustain. Energy Rev. 2007, 13, 535-551.

9. Lozano, M.A.; Carvalho, M.; Serra. L. Allocation of economic costs in trigeneration systems at variable load conditions. Energy Build. 2011, 43, 2869-2881. 
10. Carmel, Y.; Ben-Haim, Y. Info-gap robust-satisficing model of foraging behavior: do foragers optimize or satisfice? Am. Nat. 2005, 166, 633-641.

11. McIvor, A. Energy in Mining. Cleantech. 2010, 5, 16-19.

12. Australian Government Department of the Environment and Water Resources. Energy Efficiency \& Greenhouse Gas Reduction; Available online: http://commdev.org/content/document/detail/822/ (accessed on 22 October 2012).

13. Mining Association of Canada. Mining Association of Canada-Facts \& Figures. A Report on the State of the Canadian Mining Industry. Available online: http://www.miningworks.mining.ca/ miningworks/media_lib/documents/Facts_Figures_2007_E.pdf (accessed on 22 October 2012).

14. Natural Resources Canada. Mining Sector Performance; Final Report of the Federal, Provincial and Territorial Social License Task Group: Montreal, Canada, 2010. Available online: http://www.nrcan.gc.ca/sites/www.nrcan.gc.ca.minerals-metals/files/pdf/mms-smm/pubr-pubr/pdf/ EMMC_english.pdf (accessed on 22 October 2012).

15. Natural Resources Canada. Industrial Energy Prices and Background Indicators. Available online: http://oee.nrcan.gc.ca/corporate/statistics/neud/dpa/tableshandbook2/agg_00_7_e_4.cfm (accessed on 22 October 2012).

16. Levesque, M. Understanding mine heat. Master's Thesis, School of Graduate Studies, Laurentian University, Sudbury, Canada, 19 December 2011.

17. Norgate, T.; Haquea, N. Energy and greenhouse gas impacts of mining and mineral processing operations. J. Clean. Prod. 2012, 18, 266-274.

18. Fang, H.; Wu, J.; Zeng, C. Comparative study on efficiency performance of listed coal mining companies in China and the US. Energy Policy 2009, 37, 5140-5148.

19. Capehart, B.; Turner, W.; Kennedy, W. Guide to Energy Management, 5th ed.; The Fairmont Press: Atlanta, GA, USA, 2005.

20. Abdelaziz, E.; Saidur, R.; Mekhilef, D. A review on energy saving strategies in industrial sector. Renew. Sustain. Energy Rev. 2011, 15, 150-168.

21. INCO, Vale Inco Limited. 100 Years of Clean Renewable Power; Toronto, Canada, 2012. Available online: http://www.greatersudbury.ca/cms/index.cfm?app=div_earthcare \&lang=en\&currID $=6855$ (accessed on 22 October 2012).

22. Larmour, A. Empowering remote communities. North. Ontario Bus. 2007, 27. Available online: http://www.northernontariobusiness.com/Regional-News/timmins/Empowering-remote-communities. aspx (accessed on 16 November 2012).

23. Qureshi, W.; Nair, N.; Farid, M. Impact of energy storage in buildings on electricity demand side management. Energy Convers. Manag. 2011, 52, 2110-2120.

24. United Nations Industrial Development Organization. Supply-Side Management-Sustainable Energy Regulation and Policymaking for Africa; Available online: http://africa-toolkit.reeep.org/ modules/Module13.pdf (accessed on 22 October 2012).

25. Mudd, G. Global trends and environmental issues in nickel mining: Sulfides versus laterites. Ore Geol. Rev. 2010, 38, 9-26. 
26. "Coolth" is used as the noun form of "cool"; opposite of warmth. Not to be confused with cooling, which is the opposite of heating. Coolth is used, for example, in passive cooling: phase change materials can store "coolth" from the night (low temperatures), and keep the building cool during the day.

27. Liu, P.; Georgiadis, M.; Pistikopoulos, E. Modeling and optimization of polygeneration energy systems. Catal. Today 2007, 127, 347-359.

28. Deploying Large-Scale Polygeneration in Industry (D-PLOY); Bouquet, T., Ed.; The European Association for the Promotion of Cogeneration: Brussels, Belgium. Available online: http://eaciprojects.eu/iee/page/Page.jsp?op=project_detail\&prid=1506 (accessed on 22 October 2012).

29. Yokoyama, R.; Ito, K.; Kamimura, K.; Miyasaka, F. Development of a General-Purpose Optimal Operational Planning System for Energy Supply Plants. J. Energy Resour. Technol. 1994, 16, 290-296.

30. Lozano, M.; Ramos, C.; Serra, L. Cost optimization of the design of CHCP. Energy 2010, 35, 794-805.

31. Carvalho, M. Thermoeconomic and environmental analyses for the synthesis of polygeneration systems in the residential-commercial sector. Ph.D. Thesis, Department of Mechanical Engineering, University of Zaragoza, Zaragoza, Spain, 2011.

32. Carvalho, M.; Lozano, M.A.; Serra, L. Multicriteria synthesis of trigeneration systems considering economic and environmental aspects. Appl. Energy 2012, 91, 245-254.

33. Carvalho, M.; Serra, L.; Lozano, M.A. Optimal synthesis of trigeneration systems subject to environmental constraints. Energy 2011, 36, 3779-3790.

34. Carvalho, M.; Serra, L.; Lozano, M.A. Geographic evaluation of trigeneration systems in the tertiary sector. Effect of climatic and electricity supply conditions. Energy 2011, 36, 1931-1939.

35. Lozano, M.A.; Ramos, J.C.; Carvalho, M.; Serra, L.M. Structure optimization of energy supply systems in tertiary sector buildings. Energy Build. 2009, 41, 1063-1075.

36. CATERPILLAR. Natural Gas Generator Set CAT-Manufacturer Catalog. Available online: http://www.cat.com/cda/files/2842934/7/LEHE0326FM-00.pdf (accessed on 22 October 2012).

37. Goedkoop, M.; Spriensma, R. The Eco-indicator 99-A Damage-Oriented Method for Life Cycle Impact Assessment. University of Groningen, Groningen, The Netherlands. Available online: http://gasunie.eldoc.ub.rug.nl/FILES/root/2001/2665507/2665507.pdf (accessed on 22 October 2012).

38. Grossmann, I.; Caballero, J.; Yeomans, H. Advances in mathematical programming for the synthesis of process systems. Latin Am. Appl. Res. 2000, 30, 263-284.

39. Trapani, K.; Millar, D. Powering mines in the McFaulds lake area using large scale arrays of floating PV panels. In Proceedings of the 5th Mining and the Environment International Conference, Sudbury, Canada, 25-27 June 2001.

40. Erbs, D.G.; Klein, S.A.; Beckman, W.A. Estimation of degree-days and ambient temperature bin data from monthly-average temperatures. ASHARE J. 1983, 25, 60-65.

41. Rubio-Maya, C. Design optimization of a polygeneration plant fuelled by natural gas and renewable energy sources. Appl. Energy 2012, 88, 449-457.

42. Wright, M.M.; Brown, R.C.; Boateng, A.A. Distributed processing of biomass to bio-oil for subsequent production of Fischer-Tropsch liquids. Biofuels Bioprod. Biorefin. 2008, 2, 229-238. 
43. Ontario Federation of Agriculture (OFA). Assessment of Business Case for Purpose-Grown Biomass in Ontario. Available online: http://www.ofa.on.ca/uploads/userfiles/files/assessment\% 20of $\% 20$ business $\% 20$ case $\% 20$ for $\% 20$ purpose-grown $\% 20$ biomass $\% 20 \mathrm{in} \% 20$ ontario $\% 20 \mathrm{march} \%$ 202012.pdf (accessed on 22 October 2012).

44. Riley, J. Peat and Peatland Resources of Northeastern Ontario; Miland, L., Ed.; Ontario Geological Survey (OGS): Ontario, Canada, 1994; p. 155.

(C) 2012 by the authors; licensee MDPI, Basel, Switzerland. This article is an open access article distributed under the terms and conditions of the Creative Commons Attribution license (http://creativecommons.org/licenses/by/3.0/). 